\title{
Imported cholera with acute renal failure after a short business-trip to the Philippines, Germany, October 2015
}

G Slesak ${ }^{1}$, R Fleck ${ }^{1}$, D Jacob ${ }^{2}$, R Grunow ${ }^{2}$, J Schäfer ${ }^{1}$

1. Tropenklinik Paul-Lechler-Hospital, Tübingen, Germany

2. Robert Koch Institute, Berlin, Germany

Correspondence: Günther Slesak (slesak@tropenklinik.de)

Citation style for this article:

Slesak G, Fleck R, Jacob D, Grunow R, Schäfer J. Imported cholera with acute renal failure after a short business-trip to the Philippines, Germany, October 2015. Euro Surveill. 2016;21(1):pii=30099. DOI: http://dx.doi.org/10.2807/1560-7917.ES.2016.21.1.30099

Article submitted on 01 December 2015 / accepted on 07 January 2016 / published on 07 January 2016

\begin{abstract}
A German businessman developed acute watery diarrhoea after a three-day trip to the Philippines. He was admitted with severe hypotension and acute renal failure, but recovered with rapid rehydration. Vibrio cholerae $0_{1}$ serotype Ogawa was isolated. Physicians need to be aware of endemic cholera in Asia including the Philippines and consider this in their pre-travel advice.
\end{abstract}

\section{Case report}

On 4 November 2015, a 56-year-old German businessman was hospitalised in Tübingen, Germany, with acute watery, non-bloody diarrhoea (6-8x/d, no mucus), hypotension, malaise, weight loss of $5 \mathrm{~kg}$ and anuria. Onset of symptoms i.e. watery diarrhoea $(8-12 x / d)$, slight nausea and abdominal pain, was on 30 October towards the end of his return flight from a short business-trip to the Philippines, where he visited Subic Bay and Manila from 27 to 29 October. He consulted his general practitioner (GP) on 2 November, but his condition deteriorated despite increased oral fluid intake. Upon hospital admission he looked unwell, temperature and heart beats were normal, blood pressure was $70 / 50 \mathrm{mmHg}$; his skin was dry, his tongue white but still humid; otherwise physical examination was normal. He was on antihypertensive medication (amlodipine 10mg, candesartan $16 \mathrm{mg}$ ) and had a history of polycystic kidney syndrome with previously normal kidney function. He had not received a cholera vaccination prior to his trip. He had only been eating in high standard restaurants with a variety of foods including Japanese dinner (Sashimi and other raw fish) on 28 October in Subic Bay, and briefly cooked/fried seafood on 29 October in Makati, Manila. He had neither consumed tap water nor drinks with ice cubes. He was started on intravenous rehydration therapy immediately, given intravenous metoclopramide as antiemetic treatment, and encouraged to drink as much as possible.

Laboratory analyses showed creatinine of 4.4 (normal range $0.7-1.2 \mathrm{mg} / \mathrm{dl}$ ), urea 80 (normal range $10-50 \mathrm{mg} /$ $\mathrm{dl}$ ), and slightly increased CRP ( $13 \mathrm{mg} / \mathrm{L}$; normal range $0-6 \mathrm{mg} / \mathrm{L}$ ). White blood count showed normal leuco-

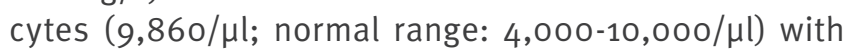
only slight neutrophilia (73\%; normal range: $50-70 \%$ ). Potassium (3.5mmol/L; normal range: $3.5-5.1 \mathrm{mmol} / \mathrm{L}$ ) and sodium (135mmol/L; normal range: $135-145 \mathrm{mmol} / \mathrm{L}$ ) were borderline low. Abdominal ultrasound confirmed a polycystic kidney disease without further obvious changes. With extensive parenteral and oral fluid and electrolyte replacement of over $5 \mathrm{~L}$ within the first 20 hours, he started producing urine and kidney function normalised rapidly (creatinine on 5 and 6 November, 2 and 3 day of admission: 2.4 and $1.4 \mathrm{mg} / \mathrm{dl}$; urea 72 and $55 \mathrm{mg} / \mathrm{dl}$, respectively). His antihypertensive therapy was halted during the whole hospital stay. He remained afebrile and diarrhoea ceased slowly.

Stool culture from 2 and 4 November (GP visit and hospital admission, respectively) grew Vibrio cholerae, fully sensitive to all standard antibiotics tested for cholera (except to nitrofurantoin). Further specification revealed $0_{1}$, Biovar El Tor, Serotype Ogawa, sodB- and ctxA-positive by real-time $P C R$, cholera toxin in vitro production was relatively low at ca. $1 \mathrm{ng} / \mathrm{ml}$ compared with $>100 \mathrm{ng} / \mathrm{ml}$ by other $c t x A$-positive isolates [1, data not shown]. After receiving the microbiological results, the option of antibiotic therapy was discussed with the patient and doxycycline (300mg single dose) was given. He was discharged on 6 November without diarrhoea or fever. Follow-up as outpatient revealed normal blood tests, including kidney function tests.

\section{Background}

After an absence of cholera cases for more than 25 years [2] cholera has again become endemic in the Philippines since 1961 [3], coinciding with the beginning of the ongoing seventh cholera pandemic [4]. Cholera typically occurs in crowded settings with poor water and sanitation infrastructure. Travel advice usually takes into consideration current outbreak reports 
but imported cholera in returning travellers to Europe is rare [5-8].

The annual incidence of cholera cases (suspected and confirmed) in the Philippines was recently calculated at 9.1 per 100,000 individuals but is likely to be higher due to under-reporting [2]. Ninety-six per cent of analysed cholera isolates in the Philippines have been of Ogawa serotype and have shown susceptibility to first-line antibotics [2]. Case fatality was calculated at $0.62 \%$ and up to $2 \%$ in outbreaks in the Philippines [2].

Mortality rates of more than $10 \%$ have been observed early in cholera epidemics but can be reduced to $<0.2 \%$ with effective therapy [4]. Severe dehydration and hypotension can lead to renal impairment. Early antibiotic treatment can decrease and shorten diarrhoea by $50 \%$ and is recommended for patients with moderate to severe dehydration [4].

\section{Discussion}

There have been no documented cholera cases imported to Germany from the Philippines for more than 15 years [9]. It is noteworthy that a short business trip to and around the capital Manila would not be considered to constitute an important risk for cholera especially with recent outbreaks being reported from more peripheral areas of the Philippines [2], and the country being listed among cholera-endemic countries with the lowest incidence rates [10]. The source of infection in the present case presumably was consumption of contaminated raw or undercooked fish or seafood in high standard restaurants.

Besides pre-travel advice on general water and food precautions, the German Society for Tropical Medicine and International Health (DTG) recommends cholera vaccination for travellers to areas with current cholera outbreaks [11]. Oral cholera vaccination has also been shown to provide some protection against traveller's diarrhoea [12], but a recent systematic review of randomised controlled trials concluded that sufficient evidence is still lacking for its use to protect travellers against diarrhoea caused by enterotoxigenic Escherichia coli [13].

Antibiotic therapy and microbiological diagnosis certainly came too late to contribute to the rapid improvement of acute renal failure in our patient, instead improvement presumably resulted from simple and rapid rehydration therapy. Aggressive fluid therapy remains the cornerstone of pre-renal failure management in cholera [14]. In view of the patients underlying kidney disease and potential benefits from antibiotics in reducing fluid loss and duration of fecal excretion of the pathogen [15], late antibiotic therapy was still performed.

The presented case demonstrates physicians in Europe should be aware of endemic cholera not only in Haiti and several African countries but also in certain parts of Asia including the Philippines [16] and consider this in pre-travel advice. Rapid rehydration therapy is needed for returning travellers presenting with acute watery diarrhoea and signs of severe dehydration.

\section{Conflict of interest}

None declared.

\section{Authors' contributions}

Günther Slesak wrote the manuscript. Günther Slesak and Johannes Schäfer treated the patient. Ralf Fleck performed the initial microbiological tests. Daniela Jacob and Roland Grunow performed microbiological tests for confirmation and further specification of the patient's pathogen. Ralf Fleck, Daniela Jacob, Roland Grunow, and Johannes Schäfer read and revised the manuscript.

\section{References}

1. Uesaka Y, Otsuka Y, Kashida M, Oku Y, Horigome K, Nair GB et al. Detection of cholera toxin by a highly sensitive beadenzyme linked immunosorbent assay. Microbiol Immunol. 1992;36(1):43-53. DOI: 10.1111/j.1348-0421.1992.tbo1641.x PMID: 1584072

2. Lopez AL, Macasaet LY, Ylade M, Tayag EA, Ali M Epidemiology of cholera in the Philippines.PLoS Negl Trop Dis. 2015;9(1):e3440. DOI: 10.1371/journal.pntd.0003440 PMID: 25569505

3. Wallace CK, Fabie AE, Mangubat O, Velasco E, Juinio C, Phillips RA. The 1961 Cholera Epidemic in Manila, Republic of the Philippines.Bull World Health Organ. 1964;30:795-810.PMID: 14215186

4. Harris JB, LaRocque RC, Qadri F, Ryan ET, Calderwood SB. Cholera.Lancet. 2012;379(9835):2466-76. DOI: 10.1016/S01406736(12)60436-X PMID: 22748592

5. European Centre for Disease Prevention and Control (ECDC). Risk of travel-associated cholera from the Dominican Republic. Stockholm: ECDC. June 2011. Available from: http://ecdc. europa.eu/en/publications/Publications/110722_TER_Risk_ Assessment_Cholera.pdf

6. Gilmour MW, Martel-Laferriere V, Lévesque S, Gaudreau C, Bekal S, Nadon C, et al. Vibrio cholerae in traveler from Haiti to Canada. Emerg Infect Dis. 2011;17(6):1124-5. DOI: 10.3201/ eid1706.110161 PMID: 21749787

7. Mascarello M, Deiana ML, Maurel C, Lucarelli C, Luzzi I, Luzzati R. Cholera with severe renal failure in an Italian tourist returning from Cuba, July 2013.Euro Surveill. 2013;18(35):20572. DOI: 10.2807/1560-7917. ES2013.18.35.20572 PMID: 24008229

8. Tarantola A, loos S, Lapidus N. Current cholera epidemics in west Africa and risks of imported cases in European countries. Euro Surveill. 2005;10(9):E050901.2.PMID: 16788225

9. Robert Koch Institut (RKI). Infektionsepidemiologisches Jahrbuch 2001-2014. [Epidemiological yearbook of infections]. Berlin: RKI. [Accessed December 2015]. Available from: http:// www.rki.de/DE/Content/Infekt/Jahrbuch/jahrbuch_node.html

10. Ali M, Nelson AR, Lopez AL, Sack DA. Updated global burden of cholera in endemic countries.PLoS Negl Trop Dis. 2015;9(6):e0003832. DOI: 10.1371/journal.pntd.0003832 PMID: 26043000

11. Deutsche Gesellschaft für Tropenmedizin und Internationale Gesundheit (DTG). Hinweise und Empfehlungen zu Impfungen. [Notes and recommendations for vaccinations]. Hamburg: DTG. May 2015. Available from: http://www.dtg.org/uploads/media/ DTG-Impfen_12_2015.pdf

12. López-Gigosos R, Campins M, Calvo MJ, Pérez-Hoyos S, Díez-Domingo J, Salleras L, et al. Effectiveness of the WC/ rBS oral cholera vaccine in the prevention of traveler's diarrhea: a prospective cohort study. Hum Vaccin Immunother. 2013;9(3):692-8. DOI: 10.4161/hv.23267 PMID: 23324573

13. Ahmed T, Bhuiyan TR, Zaman K, Sinclair D, Qadri F. Vaccines for preventing enterotoxigenic Escherichia coli (ETEC) diarrhoea. Cochrane Database Syst Rev. 2013;7:CDoo9029.PMID: 23828581 
14. Tariq M, Memon M, Jafferani A, Shoukat S, Gowani SA,

Nusrat $R$, et al. Massive fluid requirements and an unusual

$\mathrm{BUN} / \mathrm{creatinine}$ ratio for pre-renal failure in patients with

cholera. PLoS ONE. 2009;4(10):e7552. DOI: 10.1371/journal. pone.0007552 PMID: 19855842

15. Leibovici-Weissman Y, Neuberger A, Bitterman R, Sinclair D, Salam MA, Paul M. Antimicrobial drugs for treating cholera. Cochrane Database Syst Rev. 2014;6:CDoo8625.PMID:

24944120

16. WHO. Global Health Observatory Map Gallery. World: Areas reporting cholera outbreaks, 2010-2013. Geneva: WHO; 2014. Available from: http://gamapserver.who.int/mapLibrary/Files/ Maps/Global_Cholera_outbreaks.png

\section{License and copyright}

This is an open-access article distributed under the terms of the Creative Commons Attribution (CC BY 4.0) Licence. You may share and adapt the material, but must give appropriate credit to the source, provide a link to the licence, and indicate if changes were made.

This article is copyright of the authors, 2016. 